\title{
Demiclosed principle and convergence theorems for total asymptotically nonexpansive nonself mappings in hyperbolic spaces
}

\section{Li-Li Wan}

"Correspondence:

15882872311@163.com School of Science, Southwest University of Science and Technology, Mianyang, Sichuan 621010, China

\begin{abstract}
In this paper, we prove the demiclosed principle for total asymptotically nonexpansive nonself mappings in hyperbolic spaces. Then we obtain convergence theorems of the mixed Agarwal-O'Regan-Sahu type iteration for total asymptotically nonexpansive nonself mappings. Our results extend some results in the literature. MSC: 47H09; 49M05
\end{abstract}

Keywords: total asymptotically nonexpansive nonself mappings; hyperbolic space; $\triangle$-convergence

\section{Introduction}

One of the fundamental and celebrated results in the theory of nonexpansive mappings is Browder's demiclosed principle [1] which states that if $X$ is a uniformly convex Banach space, $C$ is a nonempty closed convex subset of $X$, and if $T: C \rightarrow X$ is a nonexpansive nonself mapping, then $I-T$ is demiclosed at 0 , that is, for any sequence $\left\{x_{n}\right\}$ in $C$ if $x_{n} \rightarrow x$ weakly and $\left\|(I-T) x_{n}\right\| \rightarrow 0$, then $(I-T) x=0$ (where $I$ is the identity mapping in $X$ ). Later, Chidume et al. [2] proved the demiclosed principle for asymptotically nonexpansive nonself mappings in uniformly convex Banach spaces. Recently, Chang et al. [3] proved the demiclosed principle for total asymptotically nonexpansive nonself mappings in CAT(0) spaces. It is well known that the demiclosed principle plays an important role in studying the asymptotic behavior for nonexpansive mappings. The purpose of this paper is to extend Chang's result from CAT(0) spaces to the general setup of uniformly convex hyperbolic spaces. We also apply our result to approximate common fixed points of total asymptotically nonexpansive nonself mappings in hyperbolic spaces, using the mixed Agarwal-O'Regan-Sahu type iterative scheme [4]. Our results extend and improve the corresponding results of Chang et al. [3], Nanjaras and Panyanak [5], Chang et al. [6], Zhao et al. [7], Khan et al. [8] and many other recent results.

In this paper, we work in the setting of hyperbolic spaces introduced by Kohlenbach [9]. Concretely, $(X, d, W)$ is called a hyperbolic space if $(X, d)$ is a metric space and $W$ : $X \times X \times[0,1] \rightarrow X$ a function satisfying

(I) $\forall x, y, z \in X, \forall \lambda \in[0,1], d(z, W(x, y, \lambda)) \leq(1-\lambda) d(z, x)+\lambda d(z, y)$; 
(II) $\forall x, y \in X, \forall \lambda_{1}, \lambda_{2} \in[0,1], d\left(W\left(x, y, \lambda_{1}\right), W\left(x, y, \lambda_{2}\right)\right)=\left|\lambda_{1}-\lambda_{2}\right| \cdot d(x, y)$;

(III) $\forall x, y \in X, \forall \lambda \in[0,1], W(x, y, \lambda)=W(y, x,(1-\lambda))$;

(IV) $\forall x, y, z, w \in X, \forall \lambda \in[0,1], d(W(x, z, \lambda), W(y, w, \lambda)) \leq(1-\lambda) d(x, y)+\lambda d(z, w)$.

If a space satisfies only (I), it coincides with the convex metric space introduced by Takahashi [10]. The concept of hyperbolic spaces in [9] is more restrictive than the hyperbolic type introduced by Goebel and Kirk [11] since (I)-(III) together are equivalent to $(X, d, W)$ being a space of hyperbolic type in [11]. But it is slightly more general than the hyperbolic space defined in Reich and Shafrir [12] (see [9]). This class of metric spaces in [9] covers all normed linear spaces, $\mathbb{R}$-trees in the sense of Tits, the Hilbert ball with the hyperbolic metric (see [13]), Cartesian products of Hilbert balls, Hadamard manifolds (see [12, 14]), and CAT(0) spaces in the sense of Gromov (see [15]). A thorough discussion of hyperbolic spaces and a detailed treatment of examples can be found in [9] (see also [11-13]).

A hyperbolic space is uniformly convex [16] if for $u, x, y \in X, r>0$, and $\varepsilon \in(0,2]$ there exists a $\delta \in(0,1]$ such that

$$
d\left(W\left(x, y, \frac{1}{2}\right), u\right) \leq(1-\delta) r
$$

provided that $d(x, u) \leq r, d(y, u) \leq r$, and $d(x, y) \geq \varepsilon r$.

A map $\eta:(0, \infty) \times(0,2] \rightarrow(0,1]$ is called modulus of uniform convexity if $\delta=\eta(r, \epsilon)$ for given $r>0$. The function $\eta$ is monotone if it decreases with $r$ (for a fixed $\epsilon$ ), that is,

$$
\eta\left(r_{2}, \epsilon\right) \leq \eta\left(r_{1}, \epsilon\right), \quad \forall r_{2} \geq r_{1}>0 .
$$

A subset $C$ of a hyperbolic space $X$ is convex if $W(x, y, \lambda) \in C$ for all $x, y \in C$ and $\lambda \in[0,1]$. Let $(X, d)$ be a metric space and let $C$ be a nonempty subset of $X$. $C$ is said to be a retract of $X$, if there exists a continuous map $P: X \rightarrow C$ such that $P x=x, \forall x \in C$. A map $P: X \rightarrow C$ is said to be a retraction, if $P^{2}=P$. If $P$ is a retraction, then $P y=y$ for all $y$ in the range of $P$. Recall that a nonself mapping $T: C \rightarrow X$ is said to be a $\left(\left\{v_{n}\right\},\left\{\mu_{n}\right\}, \zeta\right)$-total asymptotically nonexpansive nonself mapping if there exist nonnegative sequences $\left\{v_{n}\right\},\left\{\mu_{n}\right\}$ with $v_{n} \rightarrow 0$, $\mu_{n} \rightarrow 0$, and a strictly increasing continuous function $\zeta:[0, \infty) \rightarrow[0, \infty)$ with $\zeta(0)=0$ such that

$$
d\left(T(P T)^{n-1} x, T(P T)^{n-1} y\right) \leq d(x, y)+v_{n} \zeta(d(x, y))+\mu_{n}, \quad \forall n \geq 1, x, y \in C,
$$

where $P$ is a nonexpansive retraction of $X$ onto $C$. It is well known that each nonexpansive mapping is an asymptotically nonexpansive mapping and each asymptotically nonexpansive mapping is a $\left(\left\{v_{n}\right\},\left\{\mu_{n}\right\}, \zeta\right)$-total asymptotically nonexpansive mapping.

$T: C \rightarrow X$ is said to be uniformly L-Lipschitzian if there exists a constant $L>0$ such that

$$
d\left(T(P T)^{n-1} x, T(P T)^{n-1} y\right) \leq L d(x, y), \quad \forall n \geq 1, x, y \in C .
$$

\section{Preliminaries}

We now give the concept of $\triangle$-convergence and collect some of its properties. Let $\left\{x_{n}\right\}$ be a bounded sequence in a hyperbolic space $X$. For $x \in X$, we define

$$
r\left(x,\left\{x_{n}\right\}\right)=\limsup _{n \rightarrow \infty} d\left(x, x_{n}\right)
$$


The asymptotic radius $r\left(\left\{x_{n}\right\}\right)$ of $\left\{x_{n}\right\}$ is given by

$$
r\left(\left\{x_{n}\right\}\right)=\inf \left\{r\left(x,\left\{x_{n}\right\}\right): x \in X\right\} .
$$

The asymptotic radius $r_{C}\left(\left\{x_{n}\right\}\right)$ of $\left\{x_{n}\right\}$ with respect to $C \subset X$ is given by

$$
r_{C}\left(\left\{x_{n}\right\}\right)=\inf \left\{r\left(x,\left\{x_{n}\right\}\right): x \in C\right\} .
$$

The asymptotic center $A\left(\left\{x_{n}\right\}\right)$ of $\left\{x_{n}\right\}$ is the set

$$
A\left(\left\{x_{n}\right\}\right)=\left\{x \in X: r\left(x,\left\{x_{n}\right\}\right)=r\left(\left\{x_{n}\right\}\right)\right\} .
$$

The asymptotic center $A_{C}\left(\left\{x_{n}\right\}\right)$ of $\left\{x_{n}\right\}$ with respect to $C \subset X$ is the set

$$
A_{C}\left(\left\{x_{n}\right\}\right)=\left\{x \in C: r\left(x,\left\{x_{n}\right\}\right)=r_{C}\left(\left\{x_{n}\right\}\right)\right\} .
$$

Recall that a sequence $\left\{x_{n}\right\}$ in $X$ is said to $\Delta$-converge to $x \in X$ if $x$ is the unique asymptotic center of $\left\{u_{n}\right\}$ for every subsequence $\left\{u_{n}\right\}$ of $\left\{x_{n}\right\}$. In this case we call $x$ the $\triangle$-limit of $\left\{x_{n}\right\}$.

Lemma $1[17,18]$ Let $(X, d, W)$ be a complete uniformly convex hyperbolic space with monotone modulus of uniform convexity and $C$ a nonempty closed convex subset of $X$. Then every bounded sequence $\left\{x_{n}\right\}$ in $X$ has a unique asymptotic center with respect to $C$.

Lemma 2 [17] Let $(X, d, W)$ be a uniformly convex hyperbolic space with monotone modulus of uniform convexity $\eta$. Let $x \in X$ and $\left\{\alpha_{n}\right\}$ be a sequence in $[a, b]$ for some $a, b \in(0,1)$. If $\left\{x_{n}\right\}$ and $\left\{y_{n}\right\}$ are sequences in $X$ such that $\limsup _{n \rightarrow \infty} d\left(x_{n}, x\right) \leq c, \limsup _{n \rightarrow \infty} d\left(y_{n}, x\right) \leq c$, and $\lim _{n \rightarrow \infty} d\left(W\left(x_{n}, y_{n}, \alpha_{n}\right), x\right)=c$ for some $c \geq 0$. Then

$$
\lim _{n \rightarrow \infty} d\left(x_{n}, y_{n}\right)=0
$$

Lemma 3 [3] Let $\left\{a_{n}\right\},\left\{b_{n}\right\}$, and $\left\{c_{n}\right\}$ be sequences of nonnegative numbers such that

$$
a_{n+1} \leq\left(1+b_{n}\right) a_{n}+c_{n}, \quad \forall n \geq 1
$$

If $\sum_{n=1}^{\infty} b_{n}<\infty$ and $\sum_{n=1}^{\infty} c_{n}<\infty$, then $\lim _{n \rightarrow \infty} a_{n}$ exists.

\section{Main results}

We shall prove that a total asymptotically nonexpansive nonself mapping in a complete uniformly convex hyperbolic space $X$ with monotone modulus of uniform convexity is demiclosed. We need the following notation:

$$
\left\{x_{n}\right\} \rightarrow \omega \text { if and only if } \Phi(\omega)=\inf _{x \in C} \Phi(x),
$$

where $C$ is a closed convex subset which contains the bounded sequence $\left\{x_{n}\right\}$ and $\Phi(x):=$ $\limsup _{n \rightarrow \infty} d\left(x_{n}, x\right)$. 
Theorem 1 (Demiclosed principle for total asymptotically nonexpansive nonself mappings in hyperbolic spaces) Let $(X, d, W)$ be a complete uniformly convex hyperbolic space with monotone modulus of uniform convexity $\eta$. Let $C$ be a nonempty closed and convex subset of $X$. Let $T: C \rightarrow X$ be a uniformly L-Lipschitzian and $\left(\left\{\mu_{n}\right\},\left\{v_{n}\right\}, \zeta\right)$-total asymptotically nonexpansive nonself mapping. $P$ is a nonexpansive retraction of $X$ onto $C$. Let $\left\{x_{n}\right\} \subset C$ be a bounded approximate fixed point sequence, i.e., $\lim _{n \rightarrow \infty} d\left(x_{n}, T x_{n}\right)=0$ and $\left\{x_{n}\right\} \rightarrow p$. Then we have $T(p)=p$.

Proof By the definition, $\left\{x_{n}\right\} \rightarrow p$ if and only if $A_{C}\left(\left\{x_{n}\right\}\right)=\{p\}$. By Lemma 1 , we have $A\left(\left\{x_{n}\right\}\right)=\{p\}$. Since $\lim _{n \rightarrow \infty} d\left(x_{n}, T x_{n}\right)=0$, by induction we can prove that

$$
\lim _{n \rightarrow \infty} d\left(x_{n}, T(P T)^{m-1} x_{n}\right)=0 \quad \text { for each } m \geq 1 .
$$

In fact, it is obvious that the conclusion is true for $m=1$. Suppose the conclusion holds for $m \geq 1$, now we prove that it is also true for $m+1$. Indeed, since $T$ is uniformly $L$ Lipschitzian, we have

$$
\begin{aligned}
d\left(x_{n}, T(P T)^{m} x_{n}\right) & \leq d\left(x_{n}, T(P T)^{m-1} x_{n}\right)+d\left(T(P T)^{m-1} x_{n}, T(P T)^{m} x_{n}\right) \\
& \leq d\left(x_{n}, T(P T)^{m-1} x_{n}\right)+L d\left(x_{n}, P T x_{n}\right) \\
& \leq d\left(x_{n}, T(P T)^{m-1} x_{n}\right)+L d\left(x_{n}, T x_{n}\right) \rightarrow 0 \quad \text { as } n \rightarrow \infty .
\end{aligned}
$$

Equation (2) is proved. Hence for each $x \in X$ and $m \geq 1$, from (2) we have

$$
\Phi(x):=\limsup _{n \rightarrow \infty} d\left(x_{n}, x\right)=\limsup _{n \rightarrow \infty} d\left(T(P T)^{m-1} x_{n}, x\right) .
$$

Taking $x=T(P T)^{m-1} p, m \geq 1$ in (3), then by (1) we get

$$
\begin{aligned}
\Phi\left(T(P T)^{m-1} p\right) & =\limsup _{n \rightarrow \infty} d\left(T(P T)^{m-1} x_{n}, T(P T)^{m-1} p\right) \\
& \leq \limsup _{n \rightarrow \infty}\left\{d\left(x_{n}, p\right)+v_{m} \zeta\left(d\left(x_{n}, p\right)\right)+\mu_{m}\right\} .
\end{aligned}
$$

Letting $m \rightarrow \infty$ and taking superior limit on the both sides, we have

$$
\limsup _{m \rightarrow \infty} \Phi\left(T(P T)^{m-1} p\right) \leq \Phi(p)
$$

Assume that $T p \neq p$. Then $\left\{T(P T)^{m-1} p\right\}$ does not converge to $p$, so we can find $\varepsilon_{0}>0$, for any $k \in \mathbb{N}$, that there exists $m \geq k$ such that $d\left(T(P T)^{m-1} p, p\right) \geq \varepsilon_{0}$. We can assume $\varepsilon_{0} \in(0,2]$. Then $\frac{\varepsilon_{0}}{\Phi(p)+1} \in(0,2]$ and there exist $\theta \in(0,1]$ such that

$$
1-\eta\left(\Phi(p)+1, \frac{\varepsilon_{0}}{\Phi(p)+1}\right) \leq \frac{\Phi(p)-\theta}{\Phi(p)+\theta} .
$$

By the definition of $\Phi$ and (4), for the above $\theta$, there exists $N, M \in \mathbb{N}$ such that

$$
d\left(p, x_{n}\right) \leq \Phi(p)+\theta, \quad \forall n \geq N
$$




$$
d\left(T(P T)^{m-1} p, x_{n}\right) \leq \Phi(p)+\theta, \quad \forall n \geq N, m \geq M
$$

For $M$, there exists $m \geq M$ such that

$$
d\left(T(P T)^{m-1} p, p\right) \geq \varepsilon_{0}=\frac{\varepsilon_{0}}{\Phi(p)+\theta} \cdot(\Phi(p)+\theta) \geq \frac{\varepsilon_{0}}{\Phi(p)+1} \cdot(\Phi(p)+\theta) .
$$

Since $X$ is uniformly convex and $\eta$ is monotone, applying (5) we have

$$
\begin{aligned}
d\left(W\left(p, T(P T)^{m-1} p, \frac{1}{2}\right), x_{n}\right) & \leq\left(1-\eta\left(\Phi(p)+\theta, \frac{\varepsilon_{0}}{\Phi(p)+1}\right)\right) \cdot(\Phi(p)+\theta) \\
& \leq \frac{\Phi(p)-\theta}{\Phi(p)+\theta} \cdot(\Phi(p)+\theta) \\
& =\Phi(p)-\theta .
\end{aligned}
$$

Since $z:=W\left(p, T(P T)^{m-1} p, \frac{1}{2}\right) \neq p$, we have got a contradiction with $A\left(\left\{x_{n}\right\}\right)=\{p\}$. It follows that $T p=p$ and the proof is completed.

Theorem 2 Let $C$ be a nonempty closed and convex subset of a complete uniformly convex hyperbolic space $X$ with monotone modulus of uniform convexity $\eta$. Let $T_{i}: C \rightarrow X, i=1,2$, be uniformly L-Lipschitzian and $\left(\left\{v_{n}\right\},\left\{\mu_{n}\right\}, \zeta\right)$-total asymptotically nonexpansive nonself mappings. For arbitrarily chosen $x_{1} \in C,\left\{x_{n}\right\}$ is defined as follows:

$$
\left\{\begin{array}{l}
x_{n+1}=P W\left(x_{n}, T_{1}\left(P T_{1}\right)^{n-1} y_{n}, \alpha_{n}\right), \quad n \geq 1 \\
y_{n}=P W\left(x_{n}, T_{2}\left(P T_{2}\right)^{n-1} x_{n}, \beta_{n}\right)
\end{array}\right.
$$

where $P$ is a nonexpansive retraction of $X$ onto $C$. Assume that $\mathcal{F}=: \bigcap_{i=1}^{2} F\left(T_{i}\right) \neq \emptyset$ and the following conditions are satisfied:

(i) $\sum_{n=1}^{\infty} v_{n}<\infty$ and $\sum_{n=1}^{\infty} \mu_{n}<\infty$;

(ii) there exist constants $a, b \in(0,1)$ such that $\left\{\alpha_{n}\right\},\left\{\beta_{n}\right\} \subset[a, b]$;

(iii) there exists a constant $M>0$ such that $\zeta(r) \leq M r, r \geq 0$,

then the sequence $\left\{x_{n}\right\}$ defined by (6) $\triangle$-converges to a point in $\mathcal{F}$.

Proof We divide our proof into three steps.

Step 1 . In the sequel, we shall show that

$$
\lim _{n \rightarrow \infty} d\left(x_{n}, p\right) \text { exists for each } p \in \mathcal{F} \text {. }
$$

In fact, by conditions (1), (I), and (iii), we get

$$
\begin{aligned}
d\left(y_{n}, p\right) & =d\left(P W\left(x_{n}, T_{2}\left(P T_{2}\right)^{n-1} x_{n}, \beta_{n}\right), p\right) \\
& \leq d\left(W\left(x_{n}, T_{2}\left(P T_{2}\right)^{n-1} x_{n}, \beta_{n}\right), p\right) \\
& \leq\left(1-\beta_{n}\right) d\left(x_{n}, p\right)+\beta_{n} d\left(T_{2}\left(P T_{2}\right)^{n-1} x_{n}, p\right) \\
& \leq\left(1-\beta_{n}\right) d\left(x_{n}, p\right)+\beta_{n}\left[d\left(x_{n}, p\right)+v_{n} \zeta\left(d\left(x_{n}, p\right)\right)+\mu_{n}\right] \\
& \leq\left(1+v_{n} M\right) d\left(x_{n}, p\right)+\mu_{n}
\end{aligned}
$$


and

$$
\begin{aligned}
d\left(x_{n+1}, p\right) & =d\left(P W\left(x_{n}, T_{1}\left(P T_{1}\right)^{n-1} y_{n}, \alpha_{n}\right), p\right) \\
& \leq d\left(W\left(x_{n}, T_{1}\left(P T_{1}\right)^{n-1} y_{n}, \alpha_{n}\right), p\right) \\
& \leq\left(1-\alpha_{n}\right) d\left(x_{n}, p\right)+\alpha_{n} d\left(T_{1}\left(P T_{1}\right)^{n-1} y_{n}, p\right) \\
& \leq\left(1-\alpha_{n}\right) d\left(x_{n}, p\right)+\alpha_{n}\left[d\left(y_{n}, p\right)+v_{n} \zeta\left(d\left(y_{n}, p\right)\right)+\mu_{n}\right] \\
& \leq\left(1-\alpha_{n}\right) d\left(x_{n}, p\right)+\alpha_{n}\left(1+v_{n} M\right)\left[\left(1+v_{n} M\right) d\left(x_{n}, p\right)+\mu_{n}\right]+\alpha_{n} \mu_{n} \\
& \leq\left[1+\left(2 v_{n} M+v_{n}^{2} M^{2}\right)\right] d\left(x_{n}, p\right)+\left(2+v_{n} M\right) \mu_{n} .
\end{aligned}
$$

Combining (8) and (9), we have

$$
d\left(x_{n+1}, p\right) \leq\left(1+\sigma_{n}\right) d\left(x_{n}, p\right)+\xi_{n}, \quad \forall n \geq 1,
$$

where $\sigma_{n}=2 v_{n} M+v_{n}^{2} M^{2}, \xi_{n}=\left(2+v_{n} M\right) \mu_{n}$. Furthermore, using the condition (i), we have

$$
\sum_{n=1}^{\infty} \sigma_{n}<\infty \text { and } \sum_{n=1}^{\infty} \xi_{n}<\infty .
$$

Consequently, a combination of (10), (11), and Lemma 3 shows that (7) is proved.

Step 2. We claim that

$$
\lim _{n \rightarrow \infty} d\left(x_{n}, T_{i} x_{n}\right)=0, \quad i=1,2 .
$$

In fact, it follows from (7) that $\lim _{n \rightarrow \infty} d\left(x_{n}, p\right)$ exists for each given $p \in \mathcal{F}$. Without loss of generality, we assume that

$$
\lim _{n \rightarrow \infty} d\left(x_{n}, p\right)=c \geq 0
$$

By (8) and (13), we have

$$
\liminf _{n \rightarrow \infty} d\left(y_{n}, p\right) \leq \limsup _{n \rightarrow \infty} d\left(y_{n}, p\right) \leq \lim _{n \rightarrow \infty}\left\{\left(1+v_{n} M\right) d\left(x_{n}, p\right)+\mu_{n}\right\}=c
$$

Noting

$$
\begin{aligned}
d\left(T_{1}\left(P T_{1}\right)^{n-1} y_{n}, p\right) & \leq d\left(y_{n}, p\right)+v_{n} \zeta\left(d\left(y_{n}, p\right)\right)+\mu_{n} \\
& \leq\left(1+v_{n} M\right) d\left(y_{n}, p\right)+\mu_{n}, \quad \forall n \geq 1,
\end{aligned}
$$

by (14) we have

$$
\limsup _{n \rightarrow \infty} d\left(T_{1}\left(P T_{1}\right)^{n-1} y_{n}, p\right) \leq c
$$

Besides, by (10) we get

$$
d\left(x_{n+1}, p\right)=d\left(P W\left(x_{n}, T_{1}\left(P T_{1}\right)^{n-1} y_{n}, \alpha_{n}\right), p\right) \leq\left(1+\sigma_{n}\right) d\left(x_{n}, p\right)+\xi_{n},
$$


which yields

$$
\lim _{n \rightarrow \infty} d\left(W\left(x_{n}, T_{1}\left(P T_{1}\right)^{n-1} y_{n}, \alpha_{n}\right), p\right)=c .
$$

Now by (13), (15), (16), and Lemma 2, we have

$$
\lim _{n \rightarrow \infty} d\left(x_{n}, T_{1}\left(P T_{1}\right)^{n-1} y_{n}\right)=0 .
$$

Using the same method, we also have

$$
\lim _{n \rightarrow \infty} d\left(x_{n}, T_{2}\left(P T_{2}\right)^{n-1} x_{n}\right)=0 .
$$

By virtue of (18), we get

$$
\begin{aligned}
d\left(y_{n}, x_{n}\right) & =d\left(P W\left(x_{n}, T_{2}\left(P T_{2}\right)^{n-1} x_{n}, \beta_{n}\right), x_{n}\right) \\
& \leq d\left(W\left(x_{n}, T_{2}\left(P T_{2}\right)^{n-1} x_{n}, \beta_{n}\right), x_{n}\right) \\
& \leq \beta_{n} d\left(T_{2}\left(P T_{2}\right)^{n-1} x_{n}, x_{n}\right) \rightarrow 0 \quad \text { as } n \rightarrow \infty .
\end{aligned}
$$

Combining (17) and (19), we obtain

$$
\begin{aligned}
d\left(x_{n}, T_{1}\left(P T_{1}\right)^{n-1} x_{n}\right) & \leq d\left(x_{n}, T_{1}\left(P T_{1}\right)^{n-1} y_{n}\right)+d\left(T_{1}\left(P T_{1}\right)^{n-1} y_{n}, T_{1}\left(P T_{1}\right)^{n-1} x_{n}\right) \\
& \leq d\left(x_{n}, T_{1}\left(P T_{1}\right)^{n-1} y_{n}\right)+L d\left(y_{n}, x_{n}\right) \rightarrow 0 \quad \text { as } n \rightarrow \infty .
\end{aligned}
$$

Moreover, it follows from (17) that

$$
\begin{aligned}
d\left(x_{n+1}, x_{n}\right) & =d\left(P W\left(x_{n}, T_{1}\left(P T_{1}\right)^{n-1} y_{n}, \alpha_{n}\right), x_{n}\right) \\
& \leq d\left(W\left(x_{n}, T_{1}\left(P T_{1}\right)^{n-1} y_{n}, \alpha_{n}\right), x_{n}\right) \\
& \leq \alpha_{n} d\left(T_{1}\left(P T_{1}\right)^{n-1} y_{n}, x_{n}\right) \rightarrow 0 \quad \text { as } n \rightarrow \infty .
\end{aligned}
$$

Now by (18), (20), and (21), for each $i=1,2$, we get

$$
\begin{aligned}
d\left(x_{n}, T_{i} x_{n}\right) \leq & d\left(x_{n}, x_{n+1}\right)+d\left(x_{n+1}, T_{i}\left(P T_{i}\right)^{n} x_{n+1}\right)+d\left(T_{i}\left(P T_{i}\right)^{n} x_{n+1}, T_{i}\left(P T_{i}\right)^{n} x_{n}\right) \\
& +d\left(T_{i}\left(P T_{i}\right)^{n} x_{n}, T_{i} x_{n}\right) \\
= & d\left(x_{n}, x_{n+1}\right)+d\left(T_{i}\left(P T_{i}\right)^{n} x_{n+1}, T_{i}\left(P T_{i}\right)^{n} x_{n}\right)+d\left(x_{n+1}, T_{i}\left(P T_{i}\right)^{n} x_{n+1}\right) \\
& +d\left(T_{i}\left(P T_{i}\right)^{n} x_{n}, T_{i} x_{n}\right) \\
\leq & (1+L) d\left(x_{n}, x_{n+1}\right)+d\left(x_{n+1}, T_{i}\left(P T_{i}\right)^{n} x_{n+1}\right) \\
& +L d\left(T_{i}\left(P T_{i}\right)^{n-1} x_{n}, x_{n}\right) \rightarrow 0 \quad \text { as } n \rightarrow \infty .
\end{aligned}
$$

Therefore, (12) holds.

Step 3. Now we are in a position to prove the $\Delta$-convergence of $\left\{x_{n}\right\}$. Since $\left\{x_{n}\right\}$ is bounded, by Lemma 1, it has a unique asymptotic center $A_{C}\left(\left\{x_{n}\right\}\right)=\left\{x^{*}\right\}$. Let $\left\{u_{n}\right\}$ be any subsequence of $\left\{x_{n}\right\}$ with $A_{C}\left(\left\{u_{n}\right\}\right)=\{u\}$. Since $\lim _{n \rightarrow \infty} d\left(x_{n}, T_{1} x_{n}\right)=\lim _{n \rightarrow \infty} d\left(x_{n}, T_{2} x_{n}\right)=$ 
0 , it follow from Theorem 1 that $u \in \mathcal{F}$. By the uniqueness of asymptotic centers, we get $x^{*}=u$. It implies that $x^{*}$ is the unique asymptotic center of $\left\{u_{n}\right\}$ for each subsequence $\left\{u_{n}\right\}$ of $\left\{x_{n}\right\}$, that is, $\left\{x_{n}\right\} \Delta$-converges to $x^{*} \in \mathcal{F}$. The proof is completed.

Example 1 Let $\mathbb{R}$ be the real line with the usual norm $|\cdot|$ and let $C=[-1,1]$. Define two mappings $T_{1}, T_{2}: C \rightarrow C$ by

$$
T_{1} x= \begin{cases}-2 \sin \frac{x}{2}, & x \in[0,1], \\ 2 \sin \frac{x}{2}, & x \in[-1,0),\end{cases}
$$

and

$$
T_{2} x= \begin{cases}x, & x \in[0,1] \\ -x, & x \in[-1,0)\end{cases}
$$

It is proved in [19, Example 3.1] that both $T_{1}$ and $T_{2}$ are asymptotically nonexpansive mappings with $k_{n}=1, \forall n \geq 1$. Therefore, they are total asymptotically nonexpansive mappings with $v_{n}=\mu_{n}=0, \forall n \geq 1, \zeta(r)=r, \forall r \geq 0$. Additionally, they are uniformly $L$-Lipschitzian mappings with $L=1 . F\left(T_{1}\right)=\{0\}$ and $F\left(T_{2}\right)=\{0 \leq x \leq 1\}$. Let

$$
\alpha_{n}=\frac{n}{2 n+1}, \quad \beta_{n}=\frac{n}{3 n+1}, \quad \forall n \geq 1 .
$$

Therefore, the conditions of Theorem 2 are fulfilled.

Example 2 Let $\mathbb{R}$ be the real line with the usual norm $|\cdot|$ and let $C=[0, \infty)$. Define two mappings $T_{1}, T_{2}: C \rightarrow C$ by

$$
T_{1} x=\sin x \quad \text { and } \quad T_{2} x=x .
$$

It is proved in [20, Example 1] that both $T_{1}$ and $T_{2}$ are total asymptotically nonexpansive mappings with $v_{n}=\frac{1}{n^{2}}, \mu_{n}=\frac{1}{n^{3}}, \forall n \geq 1$. Moreover, they are uniformly $L$-Lipschitzian mappings with $L=1 . F\left(T_{1}\right)=\{0\}$ and $F\left(T_{2}\right)=\{0 \leq x<\infty\}$. Let $\left\{\alpha_{n}\right\},\left\{\beta_{n}\right\}$ be the same as in (22). Therefore, the conditions of Theorem 2 are fulfilled.

Theorem 3 Under the assumptions of Theorem 2, if one of $T_{1}$ and $T_{2}$ is demi-compact, then the sequence defined by (6) converges strongly (i.e., in the metric topology) to a common fixed point in $\mathcal{F}$.

Proof By (12) and the assumption that one of $T_{1}$ and $T_{2}$ is demi-compact, there exists a subsequence $\left\{x_{n_{i}}\right\} \subset\left\{x_{n}\right\}$ such that $\left\{x_{n_{i}}\right\}$ converges strongly to some point $p \in C$. Then by the continuity of $T_{1}$ and $T_{2}$, we get

$$
d\left(p, T_{i} p\right)=\lim _{n \rightarrow \infty} d\left(x_{n_{i}}, T_{i} x_{n_{i}}\right)=0, \quad i=1,2,
$$

which implies that $p \in \mathcal{F}$. It follows from (7) that $\lim _{n \rightarrow \infty} d\left(x_{n}, p\right)$ exists and thus $\lim _{n \rightarrow \infty} d\left(x_{n}, p\right)=0$. The proof is completed. 
Theorem 4 Under the assumptions of Theorem 2, if there exists a nondecreasing function $f:[0, \infty) \rightarrow[0, \infty)$ with $f(0)=0, f(r)>0, \forall r>0$ such that

$$
f(d(x, \mathcal{F})) \leq d\left(x, T_{1} x\right)+d\left(x, T_{2} x\right), \quad \forall x \in C,
$$

then the sequence defined by (6) converges strongly (i.e., in the metric topology) to a common fixed point in $\mathcal{F}$.

Proof By (12) and (23) we obtain $\lim _{n \rightarrow \infty} f\left(d\left(x_{n}, \mathcal{F}\right)\right)=0$. Since $f$ is nondecreasing with $f(0)=0, f(r)>0, \forall r>0$, we have

$$
\lim _{n \rightarrow \infty} d\left(x_{n}, \mathcal{F}\right)=0
$$

Now we prove that $\left\{x_{n}\right\}$ is a Cauchy sequence in $C$. In fact, it follows from (10) that, for any $p \in \mathcal{F}$,

$$
d\left(x_{n+1}, p\right) \leq\left(1+\sigma_{n}\right) d\left(x_{n}, p\right)+\xi_{n}, \quad \forall n \geq 1,
$$

where $\sum_{n=1}^{\infty} \sigma_{n}<\infty$ and $\sum_{n=1}^{\infty} \xi_{n}<\infty$. Then, for any $p \in \mathcal{F}$ and any positive integers $n, m$, we get

$$
\begin{aligned}
d\left(x_{n+m}, x_{n}\right) & \leq d\left(x_{n+m}, p\right)+d\left(x_{n}, p\right) \\
& \leq\left(1+\sigma_{n+m-1}\right) d\left(x_{n+m-1}, p\right)+\xi_{n+m-1}+d\left(x_{n}, p\right) .
\end{aligned}
$$

Since for each $x \geq 0,1+x \leq e^{x}$, we obtain

$$
\begin{aligned}
d\left(x_{n+m}, x_{n}\right) \leq & e^{\sigma_{n+m-1}} d\left(x_{n+m-1}, p\right)+\xi_{n+m-1}+d\left(x_{n}, p\right) \\
\leq & e^{\sigma_{n+m-1}+\sigma_{n+m-2}} d\left(x_{n+m-2}, p\right)+e^{\sigma_{n+m-1}} \xi_{n+m-2}+\xi_{n+m-1}+d\left(x_{n}, p\right) \\
\leq & \cdots \\
\leq & e^{\sum_{i=n}^{n+m-1} \sigma_{i}} d\left(x_{n}, p\right)+e^{\sum_{i=n+1}^{n+m-1} \sigma_{i}} \xi_{n}+e^{\sum_{i=n+2}^{n+m-2} \sigma_{i} \xi_{n+1}+\cdots} \\
& +e^{\sigma_{n+m-1}} \xi_{n+m-2}+\xi_{n+m-1}+d\left(x_{n}, p\right) \\
\leq & (1+K) d\left(x_{n}, p\right)+K \sum_{i=n}^{n+m-1} \xi_{i},
\end{aligned}
$$

where $K=e^{\sum_{i=1}^{\infty} \sigma_{i}}<\infty$. It follows from (24) that

$$
d\left(x_{n+m}, x_{n}\right) \leq(1+K) d\left(x_{n}, \mathcal{F}\right)+K \sum_{i=n}^{n+m-1} \xi_{i} \rightarrow 0 \quad \text { as } n, m \rightarrow \infty
$$

Thus $\left\{x_{n}\right\}$ is a Cauchy sequence in $C$. $C$ is complete for it is a closed subset in a complete hyperbolic space. Without loss of generality, we can assume that $\left\{x_{n}\right\}$ converges strongly to some point $p^{*} \in C$. It is easy to prove that $\mathcal{F}$ is closed. It follows from (24) that $p^{*} \in \mathcal{F}$. The proof is completed. 


\section{Competing interests}

The author declares that they have no competing interests.

\section{Acknowledgements}

Supported by General Project of Educational Department in Sichuan (No. 13ZB0182) and National Natural Science Foundation of China (No. 11426190).

Received: 18 June 2014 Accepted: 26 November 2014 Published: 16 Jan 2015

\section{References}

1. Browder, FE: Semicontractive and semiaccretive nonlinear mappings in Banach spaces. Bull. Am. Math. Soc. 74, 660-665 (1968)

2. Chidume, CE, Ofoedu, EU, Zegeye, $\mathrm{H}$ : Strong and weak convergence theorems for asymptotically nonexpansive mappings. J. Math. Anal. Appl. 280, 364-374 (2003)

3. Chang, SS, Wang, L, Joesph Lee, HW, Chan, CK: Strong and $\triangle$-convergence for mixed type total asymptotically nonexpansive mappings in CAT(0) spaces. Fixed Point Theory Appl. 2013, Article ID 122 (2013). doi:10.1186/1687-1812-2013-122

4. Agarwal, RP, O'Regan, D, Sahu, DR: Iterative construction of fixed points of nearly asymptotically nonexpansive mappings. J. Nonlinear Convex Anal. 8, 61-79 (2007)

5. Nanjaras, B, Panyanak, B: Demiclosed principle for asymptotically nonexpansive mappings in CAT(0) spaces. Fixed Point Theory Appl. 2010, Article ID 268780 (2010). doi:10.1155/2010/268780

6. Chang, SS, Wang, L, Joseph Lee, HW, Chan, CK, Yang, L: Demiclosed principle and $\triangle$-convergence theorems for total asymptotically nonexpansive mappings in CAT(0) spaces. Appl. Math. Comput. 219, 2611-2617 (2012)

7. Zhao, LC, Chang, SS, Kim, JK: Mixed type iteration for total asymptotically nonexpansive mappings in hyperbolic spaces. Fixed Point Theory Appl. 2013, Article ID 353 (2013). doi:10.1186/1687-1812-2013-353

8. Khan, AR, Fukhar-ud-din, H, Kalsoom, A, Lee, BS: Convergence of a general algorithm of asymptotically nonexpansive maps in uniformly convex hyperbolic spaces. Appl. Math. Comput. 238, 547-556 (2014)

9. Kohlenbach, U: Some logical metatheorems with applications in functional analysis. Trans. Am. Math. Soc. 357, 89-128 (2005)

10. Takahashi, W: A convexity in metric spaces and nonexpansive mappings. Kodai Math. Semin. Rep. 22, 142-149 (1970)

11. Goebel, K, Kirk, WA: Iteration processes for nonexpansive mappings. In: Singh, SP, Thomeier, S, Watson, B (eds.) Topological Methods in Nonlinear Functional Analysis. Contemporary Mathematics, vol. 21, pp. 115-123. Am. Math. Soc., Provindence (1983)

12. Reich, S, Shafrir, I: Nonexpansive iterations in hyperbolic spaces. Nonlinear Anal., Theory Methods Appl. 15, 537-558 (1990)

13. Goebel, K, Reich, S: Uniform Convexity, Hyperbolic Geometry, and Nonexpansive Mappings. Dekker, New York (1984)

14. Reich, S, Zaslavski, AJ: Generic aspects of metric fixed point theory. In: Kirk, WA, Sims, B (eds.) Handbook of Metric Fixed Point Theory, pp. 557-576. Kluwer Academic, Dordrecht (2001)

15. Bridson, M, Haefliger, A: Metric Spaces of Non-Positive Curvature. Springer, Berlin (1999)

16. Shimizu, T, Takahashi, W: Fixed points of multivalued mappings in certain convex metric spaces. Topol. Methods Nonlinear Anal. 8, 197-203 (1996)

17. Khan, AR, Fukhar-ud-din, H, Khan, MAA: An implicit algorithm for two finite families of nonexpansive maps in hyperbolic spaces. Fixed Point Theory Appl. 2012, Article ID 54 (2012). doi:10.1186/1687-1812-2012-54

18. Leustean, L: Nonexpansive iterations in uniformly convex W-hyperbolic spaces. In: Leizarowitz, A, Mordukhovich, BS, Shafrir, I, Zaslavski, A (eds.) Nonlinear Analysis and Optimization I: Nonlinear Analysis. Contemporary Mathematics, vol. 513, pp. 193-209. Am. Math. Soc., Providence (2010)

19. Guo, WP, Cho, YJ, Guo, W: Convergence theorems for mixed type asymptotically nonexpansive mappings. Fixed Point Theory Appl. 2012, Article ID 224 (2012). doi:10.1186/1687-1812-2012-224

20. Kiziltunc, H, Yolacan, E: Strong convergence theorems for two total asymptotically nonexpansive nonself mappings in Banach spaces. Fixed Point Theory Appl. 2013, Article ID 90 (2013). doi:10.1186/1687-1812-2013-90

10.1186/1687-1812-2015-4

Cite this article as: Wan: Demiclosed principle and convergence theorems for total asymptotically nonexpansive nonself mappings in hyperbolic spaces. Fixed Point Theory and Applications 2015, 2015:4

\section{Submit your manuscript to a SpringerOpen ${ }^{\circ}$ journal and benefit from:}

- Convenient online submission

Rigorous peer review

- Immediate publication on acceptance

- Open access: articles freely available online

- High visibility within the field

- Retaining the copyright to your article 